\title{
Selective criteria for differential diagnosis of infants with symptoms of congenital heart disease
}

\author{
DAVID WARBURTON, MARGARET REHAN, AND ELLIOT A SHINEBOURNE \\ Department of Paediatric Cardiology, Brompton Hospital, London
}

SUMMARY 147 case records of infants referred to the Brompton Hospital in the first year of life with a provisional diagnosis of congenital heart disease were examined. Statistical analyses were performed to evaluate selective criteria for the allocation of these infants into a group with lung disease, or into 1 of 5 major haemodynamic groups-namely, acyanotic, complete transposition of the great arteries, pulmonary outflow tract obstruction, common mixing situations, or hypoplastic left heart syndrome. Arterial $\mathrm{Po}_{2}$ in high oxygen concentration, cardiothoracic ratio, and pulmonary vascular markings on the admission chest $x$-ray; respiratory rate; $\mathrm{P}$-wave morphology, the electrical sign of the T-wave in lead $V_{4 R}$, and the presence or absence of $Q$-waves in leads $V_{4 R}$ and $V_{6}$ on the electrocardiogram were significant. A decision tree for the differential diagnosis of infants with suspected congenital heart disease into 5 haemodynamic groups and a group with lung disease is presented, and its predictive value is assessed.

In the first year of life, congenital heart disease may be suspected in the presence of cyanosis, tachypnoea, tachycardia, hepatomegaly, and failure to thrive. ${ }^{1}$ However, each of these signs may appear in seriously ill patients with disease affecting organs other than the heart. ${ }^{2-3}$ More subtle cardiac signs-such as palpation of the pulses and precordium, auscultation of the heart sounds and of the site, intensity and timing of cardiac murmurs-require special skills and are subjective. ${ }^{14}$ We present a decision tree for the differential diagnosis of infants with suspected congenital heart disease into those with lung disease and those with 1 of 5 major haemodynamic groups based on readily measurable objective criteria, chosen by statistical analysis.

\section{Methods}

147 case records of infants referred to the Brompton Hospital in the first year of life with a provisional diagnosis of congenital heart disease were examined. Data concerning the following clinical information were abstracted:

(1) Arterial blood $\mathrm{Po}_{2}$ in air, and in high oxygen concentration $\left(\mathrm{F}_{\mathrm{IO}_{2}}>0 \cdot 08\right) .{ }^{5}$

(2) Mean frontal QRS axis, determined from the electrocardiogram (ECG). ${ }^{1}$

(3) P-wave morphology: P-waves $>2.5 \mathrm{mV}$ in amplitude or $>0.08$ second in duration were considered abnormal. Tall but not prolonged $\mathrm{P}$-waves in leads II and III together with pointed P-waves in leads V1 and V2 with tall initial positivity were considered to indicate right-atrial hypertrophy. Flat-topped P-waves in leads I and II of normal height but prolonged duration with two peaks $>0.02$ second apart were considered to indicate left-atrial hypertrophy.

(4) Electrical sign of the $T$-wave in lead $V_{4} R$; positive, negative, isoelectric $\left(\mathrm{TV}_{\mathbf{4 R}}\right){ }^{1}$

(5) Voltage of the $R$-wave in lead $V_{4 R}\left(R V_{4 R}\right)$.

(6) Presence or absence of $Q$-waves in leads $V_{4} R$ $\left(\mathrm{QV}_{4} \mathrm{R}\right)$ and $\mathrm{V}_{6}\left(\mathrm{QV}_{6}\right)$.

(7) Respiratory rate was counted for 2 minutes.

(8) Cardiothoracic ratio was determined by summing the greatest diameters of the cardiac silhouette and the internal thorax on either side of the midline and dividing the thoracic by the cardiac diameter. ${ }^{1}$

(9) Pulmonary vascular markings on the initial chest $x$-ray were classified as clearly increased, clearly decreased, and indeterminate or normal. The first chest $x$-ray film taken on admission of each patient to the Brompton Hospital was interpreted blindly by a single observer (D W).

Anatomical diagnosis was obtained from cardiac catheterisation and angiography, supplemented by necropsy if performed. Information obtained from these sources was available in $92 \%$ of infants with heart disease. Of the remaining $8 \%$, all but one was 
thought to have acyanotic congenital heart disease not requiring cardiac catheterisation. The remaining patient died before investigation and necropsy was not performed.

Infants were allocated to a lung disease group or to 1 of 5 haemodynamic groups, according to the main physiological disturbance produced, which in some (but not all instances) corresponded to a specific anatomical defect. It should be stressed that none of these infants was asymptomatic and that each had been referred from another hospital to a designated centre for infants with congenital heart disease. Thus they were a group selected because of symptoms and did not represent a sample of all infants with congenital heart disease. Specifically, asymptomatic infants with heart murmurs were excluded.

The transposition of great arteries group included all patients with concordant atrio-ventricular but discordant ventriculo-arterial connections, some also had a ventricular septal defect or pulmonary stenosis. The common mixing situations group included those anomalies which resulted in admixture of the pulmonary and systemic venous return, the admixed blood being distributed to the pulmonary and systemic circulations. All patients with hypoplastic left heart syndrome had aortic atresia. The heterogeneous group with pulmonary outflow tract obstruction included patients with pulmonary atresia with or without ventricular septal defect as well as those with tricuspid atresia with restricted pulmonary flow and tetralogy of Fallot.

All those with acyanotic heart disease were thought to be in heart failure. Similarly, those with lung disease were tachypnoeic and were thought at the referring hospital possibly to be in heart failure.

Table 1 Six groups into which 147 infants were placed according to the primary anatomical diagnosis of each at cardiac catheterisation or necropsy

\begin{tabular}{|c|c|c|}
\hline $\begin{array}{l}\text { Acyanotic congenital heart disease (acy } \\
\text { Ventricular septal defect } \\
\text { Patent ductus arteriosus } \\
\text { Isolated coarctation of the aorta } \\
\text { Atrio-ventricular canal }\end{array}$ & $\begin{array}{l}\text { otic }) \\
(n=22) \\
(n=5) \\
(n=3) \\
(n=2)\end{array}$ & $\mathrm{n}=32$ \\
\hline $\begin{array}{l}\text { Hypoplastic left heart syndrome } \\
\text { Transposition of the great arteries } \\
\text { Pulmonary outflow tract obstruction } \\
\text { Tetraology of Fallot } \\
\text { Pulmonary atresia } \\
\text { Tricuspid atresia }\end{array}$ & $\begin{array}{l}(n=14) \\
(n=16) \\
(n=7)\end{array}$ & $\begin{array}{l}\mathrm{n}=\mathbf{8} \\
\mathrm{n}=27 \\
\mathrm{n}=\mathbf{3 7}\end{array}$ \\
\hline $\begin{array}{l}\text { Common mixing lesions } \\
\text { Total anomalous pulmonary venous } \\
\text { Common atrium } \\
\text { Double outlet right ventricle } \\
\text { Single ventricle }\end{array}$ & $\begin{array}{r}\text { rainage }(n=7) \\
(n=2) \\
(n=2) \\
(n=4)\end{array}$ & $\mathrm{n}=15$ \\
\hline $\begin{array}{l}\text { Lung disease } \\
\text { Respiratory distress syndrome } \\
\text { Other pulmonary problems }\end{array}$ & $\begin{array}{l}(n=11) \\
(n=17)\end{array}$ & $n=28$ \\
\hline
\end{tabular}

\section{Statistical analysis and results}

Infants were divided into 6 groups based on the anatomical diagnosis made at cardiac catheterisation or necropsy (Table 1).

Analysis of variance. This was carried out to determine whether variation of given continuous variables was greater within or between the 6 groups. The results of the analysis are illustrated by ranking the means of the haemodynamic groups for a given continuous variable and indicating the significant differences.

$\mathrm{Po}_{2}$ (in air) $\mathrm{F}=9 \cdot 32(\mathrm{P}<0 \cdot 001)$

\begin{tabular}{|c|c|}
\hline & Mean \\
\hline Acyanotic & $58 \cdot 3$ \\
\hline Lung disease & $50 \cdot 6$ \\
\hline Hypoplastic left heart syndrome & $45 \cdot 9$ \\
\hline Common mixing situations & $36 \cdot 9$ \\
\hline $\begin{array}{l}\text { Pulmonary outflow tract } \\
\text { obstruction }\end{array}$ & $34 \cdot 8$ \\
\hline Transposition of great arteries & $33 \cdot 2$ \\
\hline
\end{tabular}

The extrernes of this ranking are significantly different, a difference of about $10 \mathrm{mmHg}$ being significant at the $5 \%$ level. Common mixing situations, pulmonary outflow tract obstruction, transposition of great arteries have a lower group mean $\mathrm{Po}_{2}$ in air than aycanotic, lung disease, or hypoplastic left heart syndrome.



Significant differences below the $5 \%$ level were found between the groupings shown.

\begin{tabular}{|c|c|c|}
\hline \multicolumn{3}{|c|}{ Respiratory rate $\mathrm{F}=5 \cdot 26(\mathrm{P}<0.01)$} \\
\hline & Mean & \\
\hline Common mixing situations & $70 \cdot 3$ & respirations/ \\
\hline Hypoplastic left heart & & \\
\hline syndrome & $68 \cdot 8$ & \\
\hline $\begin{array}{l}\text { Transposition of great } \\
\text { arteries }\end{array}$ & $65 \cdot 6$ & \\
\hline Acyanotic & $63 \cdot 4$ & \\
\hline Lung disease & $59 \cdot 9$ & \\
\hline Pulmonary outflow & & \\
\hline
\end{tabular}


Pulmonary outflow tract obstruction group mean for respiratory rate was significantly lower than the other groups at the $0 \cdot 1 \%$ level.

$\left.\begin{array}{lc}\text { Cardiothoracic ratio } \mathrm{F}=3 \cdot 15(\mathrm{P}<0.001) \\ \begin{array}{l}\text { Mean } \\ \text { Hypoplastic left heart syndrome }\end{array} & 0.68 \\ \text { Acyanotic } & 0.64 \\ \text { Common mixing situation } & 0.63 \\ \text { Transposition of great arteries } & 0.61 \\ \text { Pulmonary outflow tract } & \\ \text { obstruction } & 0.60\end{array}\right\}$

The group means for hypoplastic left heart syndrome and lung disease were significantly different from each other, and from acyanotic, common mixing situations, transposition of great arteries, and pulmonary outflow tract obstruction, taken together.
The analysis of variance was not significant for QRS axis or $R V_{\mathbf{4 R}}$.

Correlation coefficient. An investigation of the relative importance of the continuous variables considered by analysis of variance for differentiating between the 6 groups was made by calculating the correlation coefficients for every possible pair of continuous variables, both overall and within the 6 groups (Table 2).

Overall, a close correlation between $\mathrm{Po}_{2}$ (in air) and $\mathrm{Po}_{2}$ (in high $\mathrm{O}_{2}$ ) was the most pronounced feature. These two criteria taken together were statistically the most accurate for differentiating between the groups. Significant correlations (Table 2) were found between $\mathrm{Po}_{2}$ (in air) and $\mathrm{Po}_{2}$ (in high $\mathrm{O}_{2}$ ) in transposition of great arteries, common mixing situations, lung disease, and pulmonary outflow tract obstruction. Positive but insignificant $r$ values were found for the hypoplastic

Table 2 Correlation coefficients for every possible pairing of 6 continuous variables both overall and within the 6 groups of infants. Only those $r$ values that achieve significance are shown

\begin{tabular}{|c|c|c|c|c|c|c|}
\hline & & $\mathrm{Po}_{2}\left(\right.$ in high $\left.\mathrm{O}_{2}\right)$ & $Q R S$-axis & $R V_{4 \mathrm{R}}$ & $\begin{array}{l}\text { Respiratory } \\
\text { rate }\end{array}$ & $\begin{array}{l}\text { Cardiothoracic } \\
\text { ratio }\end{array}$ \\
\hline $\begin{array}{l}\text { Transposition of } \\
\text { great arteries }\end{array}$ & $\begin{array}{l}\mathrm{Po}_{2} \text { (in air) } \\
\mathrm{Po}_{2} \text { (in high } \mathrm{O}_{2} \text { ) } \\
\mathrm{QRS} \text {-axis } \\
\mathrm{RV}_{4} \mathrm{R} \\
\mathrm{Respiratory} \text { rate } \\
\text { Cardiothoracic ratio }\end{array}$ & $\begin{array}{l}0.528^{* *} \\
-\end{array}$ & $\begin{array}{l}0.479^{* *} \\
0.662^{* * *} \\
-\end{array}$ & $\begin{array}{l}0.350^{*} \\
- \\
-\end{array}$ & $\begin{array}{l}- \\
\overline{0 \cdot 374^{*}} \\
-\end{array}$ & $\begin{array}{l}- \\
0.466^{*} \\
- \\
-\end{array}$ \\
\hline $\begin{array}{l}\text { Hypoplastic left } \\
\text { heart syndrome }\end{array}$ & $\begin{array}{l}\mathrm{Po}_{2} \text { (in air) } \\
\mathrm{Po}_{2} \text { (in high } \mathrm{O}_{2} \text { ) } \\
\mathrm{QRS}^{2} \text {-axis } \\
\mathrm{RV}_{4} \\
\mathrm{Respiratory} \text { rate } \\
\text { Cardiothoracic ratio }\end{array}$ & - & $\overline{-}$ & $\begin{array}{l}0.54^{*} \\
0.59^{*} \\
- \\
-\end{array}$ & $\begin{array}{l}\overline{0.78 * *} \\
\overline{0.61 *} \\
-\end{array}$ & $\begin{array}{l}- \\
z \\
z \\
-\end{array}$ \\
\hline $\begin{array}{l}\text { Common mixing } \\
\text { situations }\end{array}$ & $\begin{array}{l}\mathrm{Po}_{2} \text { (in air) } \\
\mathrm{Po}_{2} \text { (in high } \mathrm{O}_{2} \text { ) } \\
\mathrm{QRS} \text {-axis } \\
\mathrm{RV}_{4 \mathrm{R}} \\
\text { Respiratory rate } \\
\text { Cardiothoracic ratio }\end{array}$ & $\begin{array}{l}0.69 * * \\
-\end{array}$ & $\begin{array}{l}-52 * \\
-\end{array}$ & $\begin{array}{c}- \\
-\end{array}$ & $\begin{array}{l}- \\
- \\
-\end{array}$ & $\begin{array}{l}0.55^{*} \\
0 \cdot 54^{*} \\
- \\
0 \cdot 47^{*} \\
-\end{array}$ \\
\hline Lung disease & $\begin{array}{l}\mathrm{Po}_{2} \text { (in air) } \\
\mathrm{Po}_{2} \text { (in high } \mathrm{O}_{2} \text { ) } \\
\mathrm{QRS} \text {-axis } \\
\mathrm{RV}_{4} \mathrm{R} \\
\text { Respiratory rate } \\
\text { Cardiothoracic ratio }\end{array}$ & $0.473^{* * *}$ & - & $\begin{array}{l}\overline{0.556^{* *}} \\
0.519^{* *} \\
-\end{array}$ & $\begin{array}{l}- \\
0.567^{* *} \\
- \\
-\end{array}$ & $\begin{array}{l}- \\
- \\
\overline{0.470 * *} \\
-\end{array}$ \\
\hline Acyanotic & $\begin{array}{l}\mathrm{Po}_{2} \text { (in air) } \\
\mathrm{Po}_{2} \text { (in high } \mathrm{O}_{2} \text { ) } \\
\mathrm{QRS} \text {-axis } \\
\mathrm{RV}_{4 \mathrm{R}} \\
\text { Respiratory rate } \\
\text { Cardiothoracic ratio }\end{array}$ & - & - & - & $\begin{array}{l}- \\
- \\
0.474^{* *} \\
0.464^{* *} \\
-\end{array}$ & $\begin{array}{l}- \\
- \\
0.407 * \\
-\end{array}$ \\
\hline $\begin{array}{l}\text { Pulmonary outflow } \\
\text { tract obstruction }\end{array}$ & $\begin{array}{l}\mathrm{Po}_{2} \text { (in air) } \\
\mathrm{Po}_{2} \text { (in high } \mathrm{O}_{2} \text { ) } \\
\mathrm{QRS}^{2} \text {-axis } \\
\mathrm{RV}_{4} \mathrm{R} \\
\mathrm{Respiratory} \text { rate } \\
\text { Cardiothoracic ratio. }\end{array}$ & $\begin{array}{l}0.834^{* * *} \\
-\end{array}$ & - & $\begin{array}{l}- \\
-\end{array}$ & $\begin{array}{l}- \\
- \\
-\end{array}$ & $\begin{array}{l}- \\
z \\
z\end{array}$ \\
\hline
\end{tabular}

$* * \mathbf{P}<0.001, * * \mathrm{P}<0.01, * \mathrm{P}<0.05$. 
left heart syndrome and acyanotic groups. Overall statistical significance was not achieved with any other pairings of continuous variables.

The $\chi^{2}$ test. This was applied to the discontinuous variables (Tables 3-7).

\section{$P$-wave morphology}

Normal P-wave morphology predominated in all groups. Right-atrial hypertrophy was occasionally seen in pulmonary outflow tract obstruction, acyanotic, common mixing situations, and transposition of great arteries. Left-atrial hypertrophy was seen once in acyanotic and once in transposition of great arteries.

Table 3 P-wave morphology

\begin{tabular}{llll}
\hline & Normal & $\begin{array}{l}\text { Right atrial } \\
\text { hypertrophy }\end{array}$ & $\begin{array}{l}\text { Left atrial } \\
\text { hypertrophy }\end{array}$ \\
\hline $\begin{array}{l}\text { Pulmonary outflow } \\
\text { tract obstruction }\end{array}$ & 26 & 4 & 0 \\
$\begin{array}{l}\text { Acyanotic } \\
\begin{array}{l}\text { Lung disease } \\
\text { Hypoplastic left } \\
\text { heart syndrome }\end{array}\end{array}$ & 22 & 3 & 1 \\
$\begin{array}{c}\text { Common mixing } \\
\text { situations }\end{array}$ & 10 & 0 & 0 \\
$\begin{array}{c}\text { Transposition of } \\
\text { great arteries }\end{array}$ & 8 & 0 & 0 \\
\hline 2 & 22 & 3 & 0 \\
$\chi_{10}^{2}=20 \cdot 23, P<0.05$. & & & 1 \\
\hline
\end{tabular}

Table 4 Electrical sign of $T$-wave in lead $V_{4 \mathbf{R}}$

\begin{tabular}{lccc}
\hline & Positive & Negative & Isoelectric \\
\hline Pulmonary outflow & & & \\
$\quad$ tract obstruction & 19 & 6 & 3 \\
Acyanotic & 4 & 19 & 4 \\
Lung disease & 6 & 12 & 3 \\
Hypoplastic left & 4 & 5 & 2 \\
$\quad$ heart syndrome & 4 & 8 & 0 \\
$\quad$ rituations & 5 & 16 & 3 \\
\hline greansposition of & 9 & 16 & \\
\hline
\end{tabular}

$\chi_{10}^{2}=21.57, \mathrm{P}<0.05$.

Table 5 Presence or absence of $Q$-wave in lead $V_{6}$

\begin{tabular}{lll}
\hline & Present & Absent \\
\hline Pulmonary outflow tract & 4 & \\
obstruction & 4 & 23 \\
Acyanotic & 5 & 23 \\
Lung disease & 2 & 20 \\
Hypoplastic left heart & 4 & 6 \\
$\quad$ syndrome & 6 \\
$\begin{array}{l}\text { Common mixing situations } \\
\text { Transposition of great }\end{array}$ & 6 & 23 \\
\hline arteries & 2 & \\
\hline
\end{tabular}

$x_{5}^{2}=14 \cdot 32, P<0.02$.
Table 6 Presence or absence of $Q$-wave in lead $V_{6}$

\begin{tabular}{lcc}
\hline & Present & Absent \\
\hline Pulmonary outflow tract & 14 & 12 \\
$\quad$ obstruction & 20 & 7 \\
Acyanotic & 11 & 11 \\
Lung disease & 1 & 9 \\
Hypoplastic left heart & 11 \\
syndrome & 0 & 17 \\
Common mixing situations & 0 & \\
Transposition of great & 7 & \\
arteries & &
\end{tabular}

Table 7 Pulmonary vascular markings on initial chest $x$-ray

\begin{tabular}{lrrl}
\hline & Increased & Decreased & $\begin{array}{c}\text { Indeterminate } \\
\text { or normal }\end{array}$ \\
\hline $\begin{array}{l}\text { Pulmonary outflow } \\
\text { tract obstruction }\end{array}$ & 5 & 20 & 6 \\
$\begin{array}{l}\text { Acyanotic } \\
\text { Lung disease }\end{array}$ & 27 & 1 & 2 \\
$\begin{array}{l}\text { Hypoplastic left } \\
\text { heart syndrome }\end{array}$ & 0 & 0 & 18 \\
$\begin{array}{l}\text { Common mixing } \\
\text { situations }\end{array}$ & 3 & 2 & 3 \\
$\begin{array}{l}\text { Transposition of } \\
\text { great arteries }\end{array}$ & 8 & 1 & 5 \\
\hline$\chi_{10}^{2}=179 \cdot 32, P<0.001$. & 4 & 7 \\
\hline
\end{tabular}

$T V_{4 \mathrm{R}}$

Positive $\mathrm{T}$-waves predominated in pulmonary outflow tract obstruction. Negative T-waves predominated in the acyanotic, lung disease, and transposition of great arteries groups.

$Q V_{4 \mathrm{R}}$

Q-waves were predominantly absent from lead $V_{4} R$ in the acyanotic, lung disease, pulmonary outflow tract obstruction, and transposition of great arteries groups. Q-waves were present in and absent from lead $V_{4 R}$ in equal numbers in the common mixing situations and hypoplastic left heart syndrome groups.

$Q V_{\text {B }}$

Q-waves were present in lead $V_{6}$ in the majority of infants in the acyanotic group. Q-waves were present in and absent from lead $V_{6}$ in equal numbers in the pulmonary outflow tract obstruction and lung disease groups. The transposition of great arteries, and hypoplastic left heart syndrome groups were predominantly without $Q$-waves in lead $\mathrm{V}_{6}$. The common mixing group had no $Q$-waves in lead $V_{6}$.

\section{Pulmonary vascular markings}

In the pulmonary outflow tract obstruction group, pulmonary vascular markings were predominantly decreased, while in the acyanotic group, pulmonary 
vascular markings were predominantly increased. In the lung disease group, normal pulmonary vascular markings were seen in all the cases. The hypoplastic left heart group had equal numbers of cases with increased, decreased, and normal pulmonary vascular markings.

\section{Discussion}

There have been many attempts to classify congenital heart defects on the basis of clinical presentation. ${ }^{36-10}$ We chose several objective and readily measured criteria and tested their statistical power in differentiating between 6 groups of patients: 5 with congenital heart disease and 1 with lung disease (Table 1).

Levin et al. ${ }^{11}$ noted that $65 \%$ of 66 infants with
D-transposition of great arterıes were tachypnoeic on presentation and that other signs of a major congenital cardiac anomaly were usually absent in these infants. In the present study, tachypnoea was seen in all groups except the pulmonary outflow tract obstruction group.

We noted that $\mathrm{Po}_{2}$ (in air) alone did not differentiate reliably between acyanotic and other lesions, whereas the addition of $\mathrm{Po}_{2}$ (in high $\mathrm{O}_{2}$ ) (the hyperoxia test) improved the reliability of differentiating between acyanotic and other lesions to the $1 \%$ level of significance. We agree with Jones et al. ${ }^{5}$ that in infants who achieve a $\mathbf{P o}_{2}$ (in high $\mathrm{O}_{2}$ ), >150 $\mathrm{mmHg}$, cyanotic congenital heart disease may be effectively ruled out. However, episodes of enhanced cyanosis may be seen in infants with a ductus-dependent circulation during

Table 8 A decision tree for the differential diagnosis of infants with symptoms of congenital heart disease into a group with lung disease and 5 other major haemodynamic groups based on statistical analysis of selective criteria. The decision tree is constructed in the form of a flow diagram. In order to allocate a particular infant prospectively to 1 of the 6 groups, the data obtained from individual selective criteria should be combined sequentially following the steps outlined in the flow diagram. (Levels of significance at each step are indicated).

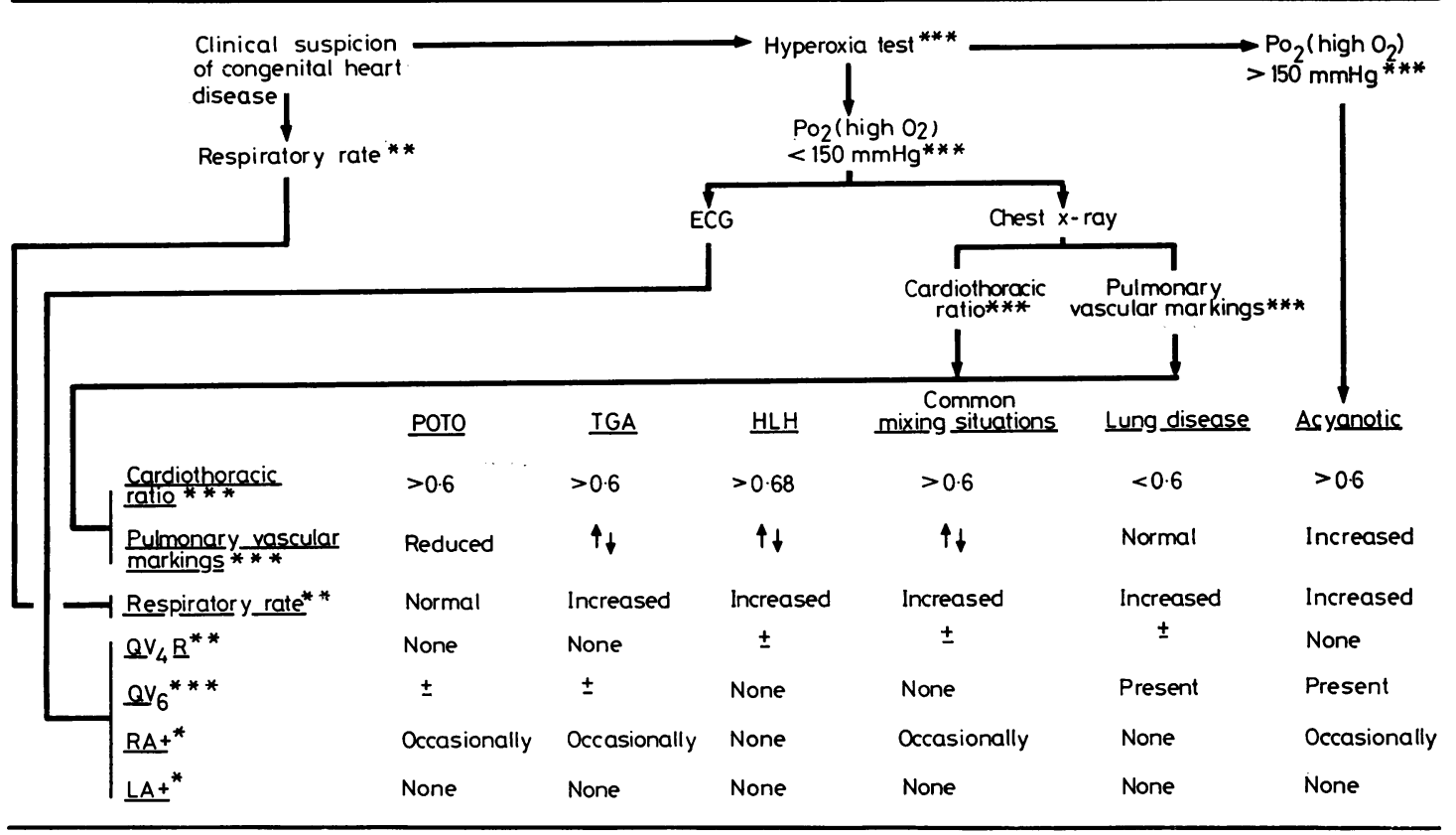

\begin{tabular}{|c|c|c|c|}
\hline Acyanotic & Acyanotic congenital heart disease & РОтО & Puimonary outflow tract obstruction \\
\hline ECG & Electrocardiogram & $Q V_{4} R$ & $Q$-wave in lead $V_{4} R$ on ECG \\
\hline $\mathrm{HLH}$ & Hypoplastic left heart syndrome & $Q V_{6}$ & $Q$-wave in lead $V_{6}$ on $E C G$ \\
\hline $\mathrm{LA+}$ & Lett atrial hypertrophy diagnosed by ECG & RA+ & Right atrial hypertrophy diagnosed by ECG \\
\hline \multirow[t]{2}{*}{ TGA } & of great arteries & & \\
\hline & $P<0.001 * * * \quad P<0.01 * *$ & $5 *$ & \\
\hline
\end{tabular}


Example 1. A 7-day-old boy weighing $3 \cdot 2 \mathrm{~kg}$, born at 38 weeks by elective caesarean section, had tachypnoea (60 respirations/min) and a murmur which gave rise to a suspicion of congenital heart disease. $\mathrm{Po}_{2}$ (in high $\mathrm{O}_{2}$ ) was $113 \mathrm{mmHg}$. Cardiothoracic was $\mathbf{0 . 5 5}$. Pulmonary vascular markings were normal. Tachypnoea was present. Q-wave was absent in lead $V_{4_{R}}$ and present in lead $V_{6}$. There was no left or right atrial hypertrophy on ECG. The infant was classified in the lung disease group. This infant recovered over the next 3 days and was thought to have transient tachypnoea of the newborn.

Example 2. An 8-week-old girl was cyanosed and had failed to gain weight. $\mathrm{Po}_{2}$ (in high $\mathrm{O}_{2}$ ) was $67 \mathrm{mmHg}$. Cardiothoracic ratio was 0.65 and pulmonary vascular markings were reduced. Respiratory rate was $40 / \mathrm{min}$. Q-waves were absent from lead $V_{4_{R}}$ and present in lead $V_{6}$. Right atrial hypertrophy was present in ECG. This infant was classified in the pulmonary outflow tract obstruction group. At cardiac catheterisation she proved to have situs solitus, concordant pulmonary atresia with ventricular septal defect.

the administration of high $\mathrm{O}_{2} \cdot{ }^{14}$ The hyperoxia test must be used with caution when the presence of a ductus-dependent circulation is suspected.

On the initial chest $x$-ray film, taken on admission to the Brompton Hospital, a cardiothoracic ratio $>0.6$ was associated with heart disease, whereas a cardiothoracic ratio $<0.6$ was most likely to be seen with lung disease $(P<0 \cdot 01)$. A particularly large cardiothoracic ratio was seen in the hypoplastic left heart syndrome group $(P<0 \cdot 05)$. The assessment of pulmonary vascular markings was subjective. However, with the division of pulmonary vascular markings into clearly increased, clearly decreased, and indeterminate or normal groups, a close correlation was observed between pulmonary vascular markings and expected pulmonary blood flow, those with high flows having increased respiratory rates. Infants with a low respiratory rate and reduced pulmonary vascular markings were most likely to be found in the pulmonary outflow tract obstruction group $(P<0 \cdot 05)$.

We did not find the ECG to be as helpful as the hyperoxia test or the chest $x$-ray film in differentiating between infants in the 6 groups. The analysis of variance was not significant for QRS axis, and the $\chi^{2}$ test was not significant for $R_{4} \mathbf{R}$.

Shinebourne et al. ${ }^{12}$ however, pointed out the significance of a superior QRS-axis in the differential diagnosis of infants with congenital heart disease. It is probable that with a larger series of patients in which the study groups could be broken down into individual anomalies, some of the ECG criteria
Example 3. A 10-day-old girl who weighed $3 \cdot 8 \mathrm{~kg}$ after a vaginal delivery at term became listless and refused to feed. $\mathrm{Po}_{2}$ (in high $\mathrm{O}_{2}$ ) was $100 \mathrm{mmHg}$. Cardiothoracic ratio was $0 \cdot 69$. Pulmonary vascular markings were increased. Respiratory rate was 100 respirations/min. Q-waves were present in lead $V_{4 R}$ and absent from lead $V_{6}$. There was no left or right atrial hypertrophy on ECG. The infant was classified in the hypoplastic left heart syndrome group. On echocardiography, aortic atresia with hypoplasia of the left ventricle and mitral valve was visualised. Aortic atresia was confirmed on aortography.

When the decision tree was used to classify the infants in the study, all 8 infants were classified correctly to the hypoplastic left heart group, 20 of 28 infants were classified correctly to the lung disease group, 28 of 32 infants were classified correctly to the acyanotic group, 23 of 27 infants were classified correctly to the transposition of great arteries group, 29 of 37 infants were classified correctly to the pulmonary outflow tract obstruction group, and 12 of 15 infants were correctly classified to the common mixing group.

might prove significant. For example, distinguishing patients with pulmonary atresia and an intact ventricular septum from those with an additional ventricular septal defect might result in significant differences in $R V_{4}$; similarly a $Q R S$-axis between 270 and $360^{\circ}$ (superior axis) might distinguish patients with atrioventricular canal from the rest of the acyanotic group, or those with tricuspid atresia from the remainder of those with pulmonary outflow tract obstruction. Looking at individual anomalies in the present study, cases of hypoplastic left heart syndrome, Fallot's tetralogy, total anomalous pulmonary venous drainage, and ventricular septal defect were seen with a superior-QRS axis.

$\mathrm{P}$-wave morphology, electrical sign of the T-wave in lead $V_{4}$, and the presence or absence of Q-waves in leads $V_{4} R$ and $V_{6}$ could also be helpful in differentiating between the study groups $(\mathrm{P}<0.05$, $0.05,0.02$, and 0.001 respectively).

Despite relatively small numbers of infants with individual anomalies, and the retrospective hature of our data, we were able to show significant correlations between certain selective criteria for the differential diagnosis of infants with symptoms of congenital heart disease into 5 major haemodynamic groups and a group with lung disease. Clearly, the diagnosis of each anomaly must rest on more definitive methods of investigation. Nevertheless, the decision tree presented in Table 8 has potentially useful applications in clinical practice. When the table was used to classify the babies in the present study, $81 \%$ were classified correctly. 


\section{References}

1 Nadas A S, Fyler D C. Pediatric cardiology. Philadelphia: Saunders, 1972.

2 Avery M E, Fletcher B D. The lung and its disorders in the newborn infant. Major Problems in Clinical Pediatrics. Vol. 5. Philadelphia: Saunders, 1974.

3 Rowe R D, Mehrizi A. The neonate with congenital heart disease. Philadelphia: Saunders, 1968.

4 Rudolph A M. Congenital diseases of the heart. Chicago: Year Book Medical Publishers, 1974.

5 Jones R W A, Baumer J H, Joseph M C, Shinebourne E A. Arterial oxygen tension and the response to oxygen breathing in the differential diagnosis of congenital heart disease in infancy (abstract). Br Heart $J$ 1976; 38: 314.

6 Abbott M E. Atlas of congenital heart disease. New York: New York Heart Association, 1936.

7 Cabrera E, Monroy J R. Systolic and diastolic loading of the heart. I. Physiologic and clinical data. Am Heart J 1952; 43: 661-8.

${ }^{8}$ Bing R J. Congenital heart disease. An introduction and classification. Am J Med 1952; 12: 77-96.
9 Graettinger J S, Gasul B M. Congenital malformations of the heart with correlation of the clinical and physiologic features. In: Gordon B L, ed. Cardiopulmonary physiology. New York: Grune \& Stratton, 1960.

10 Kincaid $\mathrm{O} W$. Roentgenologic consideration in the diagnosis of congenital heart disease. I. Mod Concepts Cardiovasc Dis 1961; 30: 657-61.

11 Levin D L, Paul M H, Muster A J, Newfeld A E, Waldman D J. D-transposition of the great vessels in the neonate: a clinical diagnosis. Arch Intern Med 1977; 137: 1421-5.

12 Shinebourne E A, Haworth S G, Anderson R H, Ulgur A. Differential diagnosis of congenital heart disease in the first 3 months of life; significance of a superior (left) QRS axis. Arch Dis Child 1974; 49: 729-33.

Correspondence to Dr D Warburton, NeonatalRespiratory Disease Division, Children's Hospital of Los Angeles, 4650 Sunset Boulevard, Los Angeles, California 90054, USA.

Received 23 October 1979 